\title{
Urinary schistosomosis in patients of rural medical health centers in Kwale county, Kenya
}

\author{
A. KAIGLOVÁ ${ }^{1, *}$, M. J. S. CHANGOMA², J. ŠPAJDELOVÁ1 \\ 1Department of Laboratory Medicine, School of Health Sciences and Social Work, Trnava University, Univerzitné nám. 1, \\ 91843 Trnava, Slovakia, ${ }^{*} E-m a i l: ~ a l z b e t a . k a i g l o v a @ t r u n i . s k ; ~ '{ }^{2}$ wale Research Site, NUITM-KEMRI Project, Resource Centre Bldg., \\ Next to Kwale Hospital, P.O.BOX 134, Kwale, Kenya; ${ }^{3}$ Specific Department of Faculty of Health Sciences and Social Work, \\ Trnava University in Kenya in Kwale region, Kenya
}

Article info

Received February 22, 2019 Accepted October 10, 2019

\section{Summary}

Urinary schistosomosis is a serious public health problem prevalent in low-income rural regions of sub-Saharan Africa, including coastal part of Kenya. Praziquantel administration to school-aged children is the prevailing tool of schistosomosis control in these regions. The aim of our study was to find out if this control strategy can lead to interruption of parasite trasmission and disease elimination. During February and March 2018, the occurrence of urinary schistosomosis in volunteers of primary health care facilities in Kwale County, Kenya was examined and the occurrence of infected intermediate hosts Bulinus globosus in local water resources was monitored. Participants completed a questionnaire concerning source of water for household purposes, type of housing and health status and were asked to provide urine samples. Diagnosis of urinary schistosomosis was established by detection of Schistosoma haematobium eggs in urine specimens microscopically, using filtration method. Infected B. globosus snails were detected using cercaria shedding tests. From the hemolymph of snails, prepatent period of infection was identified by polymerase chain reaction (PCR). The presence of urinary schistosomosis was detected in $15.07 \%$ (69 out of 451) of study participants. Cercaria shedding test was positive in 2 particular sites of river Pengo and Tsanganyiko. Genetic material (haemolymph) of 68 B. globosus snails tested by Dral PCR revealed 7 Schistosoma spp. positive samples. Six of seven Dral positive snails were infected by $S$. haematobium, as it was detected by Sh110/SmS1 PCR. The study revealed, that the disease was still present in the region studied and the transmission was not interrupted. The rate of infection was significantly influenced by the water supplies used for household purposes and the type of housing.

Keywords: Schistosoma haematobium; urinary schistosomosis; parasite transmission

\section{Introduction}

Urinary schistosomosis (known also as snail fever or bilharzia), caused by parasitic blood trematode $S$. haematobium, is prevalent in regions with lack of clean water and sanitation systems in the home, often in rural regions of sub-Saharan Africa (Bruun and Aagaard-Hansen, 2008). Humans become infected when they come in contact with contaminated water sources infested by $S$. haematobium cercariae that are released from intermediate hosts - freshwater snails of the genus Bulinus.

Urinary schistosomosis causes a serious public health problem in coastal parts of Kwale county, Kenya. Regular praziquantel administration to school-aged children over the past years might lower the disease prevalence and reduce morbidity. It seems that interruption of transmission might be essential for the successful elimination of the disease. The intermediate host - freshwater snail of

\footnotetext{
$\bar{*}$ - corresponding author
} 
the genus Bulinus - releases cercarial larvae in the water. If they come into contact with human skin, they penetrate it within minutes and migrate via the blood circulation to the portal vein. In this place they develop into the tiny immature flukes called schistosomulae. In the portal vein schistosomulae mature, copulate, and the constantly paired couples migrate to perivesicular venous plexus. Fertilised females lay eggs, which may move through the vessels and enter the cavity of the bladder to be excreted. Ciliated miracidia released from the eggs after hatching move actively and seek for their intermediate host, thus completing the life cycle. However, some of the eggs may be retained in tissues of the hosts inducing immune response and inflammation process, which may lead to various pathological consequences. Untreated infection can lead into painful urination, suprapubic discomfort, haematuria, inflammatory and granulomatous lesions in the male and female urinary systems. Anaemia, bladder cancer, kidney failure as well as co-infection with some viruses, bacteria, or parasites are another possible complications of disease in the later stages (El Ridi and Tallima, 2013). In spite of the fact, that people with mild worm burdens can have minimal or no symptoms, the health implications of the disease may be far-reaching (Gryseels et al., 2006). Efforts to control morbidity of schistosomosis is increasing in countries of sub-Saharan Africa, including endemic region parts of Kenya. In these areas, $S$. haematobium infection control is focused on regular administration of single dose of praziquantel to school-aged children, referred to as mass drug administration (MDA) (N'goran et al., 2003; Muhumuza et al.,2014).

The main objective of our study was to evaluate the impact of the control strategies on the transmission of schistosomiasis in the area studied. Therefore, during February and March 2018, the occurrence of urinary schistosomosis in patients of primary health care facilities was examined and at the same time the occurrence of infected intermediate hosts Bulinus globosus in selected local water resources was monitored.

\section{Materials and Methods}

Specimens of urine and questionnaire answers were obtained from individuals/patients of cooperating primary health care facilities in Kwale County, Kenya - Mwachiga Dispensary (Kinango Constituency, Kinango Location, Dumbule Sub Location), Mwaluphamba Dispensary (Matuga Constituency, Mwaluphamba Location, Mlafyeni Sub Location), Bilashaka Dispensary (Matuga Constituency, Tsimba Golini Location, Tsimba Golini Sub Location) a Mbuwani Dispensary (Msambweni Constituency, Diani Location, Msambweni Sub Location). Snails were collected from the selected places of water bodies localised on rivers Mbeto, Kombo, Bora, Ndugunane, Jarumani and Ramoyo in the surroundings of Mwachinga Dispensary; rivers Bechone Swabirina, Mbadzi, Tsanganyiko, Bangoni, Komanazilale, Mzizima in the surroundings of Mwaluphamba Dispensary as well as rivers Buburu, Kivumiro, Chimambani and Mbararani in the surroundings of Bilashaka Dispensary (Fig.1).
All of these areas are endemic only for urinary schistosomiasis caused by $S$. haematobium. Inhabitants of these remote villages work mostly as peasant farmers or casual workers. Most of them declare an acces to sanitation system in the form of pit latrines and access to clean water - e.g., in Mwachinga Japan International Cooperation Agency constructed water kiosk for villagers. However, they still use water from lakes, rivers and ponds for watering animals, bathing or washing clothes, as was shown by questionnaire results. In the framework of deworming programme, in Mwaluphamba, Bilashaka and Mbuwani, co-administration of praziquantel (against urinary schistosomiasis) and albendazole (against soil-transmitted helminth infections) to community and school children was performed once a year in follwoing years: 2004, 2005,2007, 2009 and 2012. To date, praziquantel is applied in these areas to school-children once a year. In Mwachinga, praziquantel was administered to both school children and community yearly from $1998-2007$. From 2010 to date, it is applied to school-children once a year.

\section{Inclusion/exclusion criteria of the study participants}

The aim of our study was to monitor $S$. haematobium infection in volunteers of different ages to be able to evaluate their contribution to the disease transmission. Therefore, all patients of primary health care facilities who were willing to complete a questionnaire and sign informed consent were enrolled into the study, except menstruating female volunteers. The urine samples were analyzed the same day in the laboratory section (corner/room) of these cooperating health care centers (dispensaries).

Informed consent, questionnaire, and urine sample collection From February 19th - March 16th, 2018 randomly selected individuals/patients of primary health care facilities were contacted by local health officials who explained to them about voluntary participation and objectives of the study. Parents/care-takers were asked to give their ageement on behalf of participating minors. After acceptance to be enrolled in the study, participants (or parents/ care-takers) were asked to sign informed consent and complete a short questionnaire concerning health status, source of water used, previous history of praziquantel administration and awareness of disease transmission. Samples of urine were assigned with the identification number and processed the same day in the laboratory section of health facilities. In urine specimens, macrohematuria was detected visually. For the presence of microhaematuria in the urine samples, diagnostic strips Hemophan (Erba Lachema Ltd., Brno, Czech Republic) working on the basis of chemical reaction of hemoglobin with chemicals on the reagent pad of the strip were used. Then, $10 \mathrm{ml}$ of urine sample was passed through the Nucleopore membrane filter $(25 \mathrm{~mm}$, pore size $8 \mu \mathrm{m})$. The filter was then placed on a microscope glass slide and the eggs of $S$. haematobium were detected under the microscope at a magnification of $x 400$. The intensity of infection was expressed as light (L), medium $(M)$ or heavy $(\mathrm{H})$ according to the number of eggs per $10 \mathrm{ml}$ 


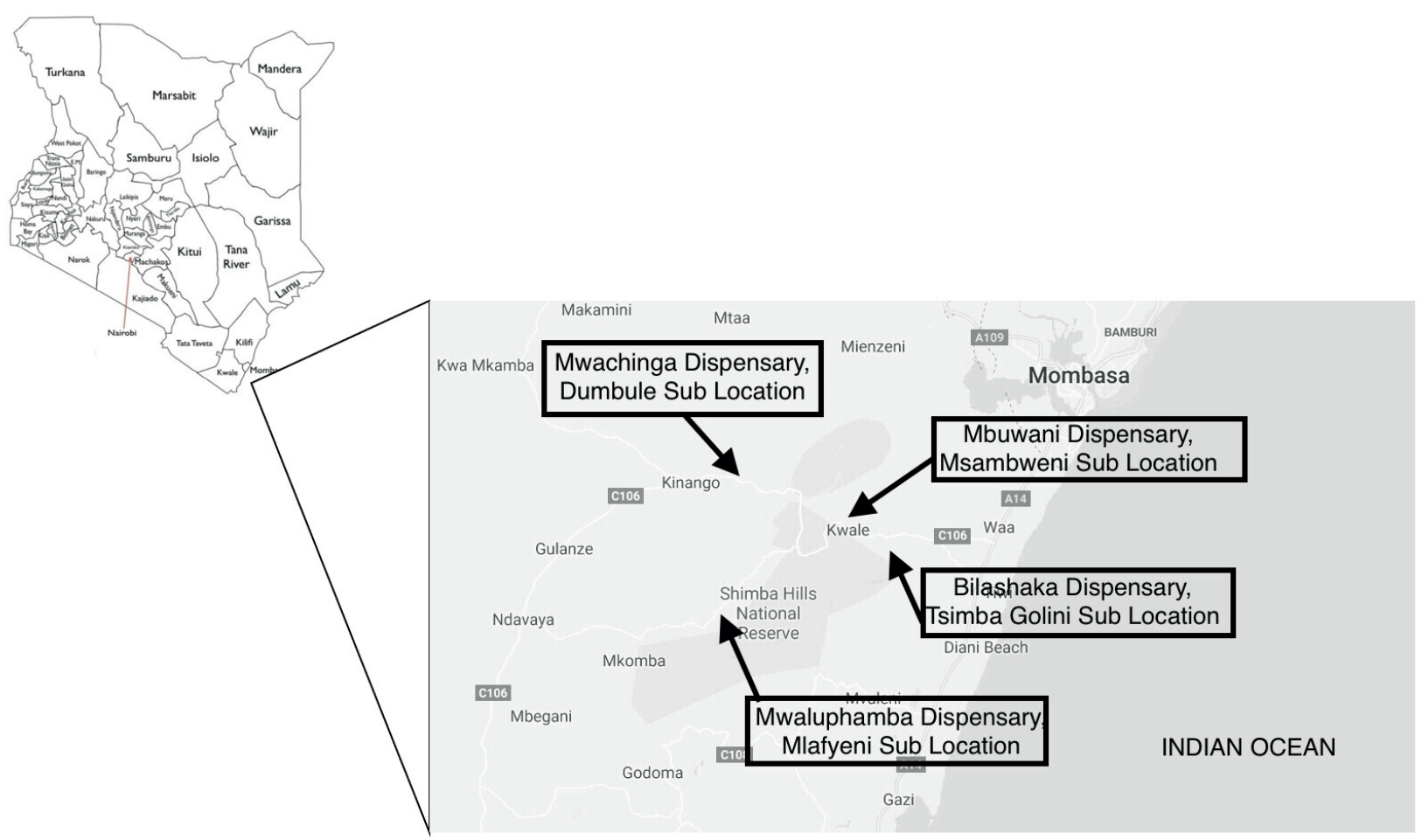

Fig.1. Map showing the location of areas included in survey, Kwale County, Kenya.

of urine (light: 1 - 4 eggs, medium: $5-49$ eggs, heavy: $\geq 50$ eggs). Participants found positive for $S$. haematobium infection throughout the study were treated with praziquantel in cooperation with primary health care facility workers.

\section{Field procedures}

Cercariae of infected freshwater snails were detected with the assistance of NUITM-KEMRI workers using cercaria shedding test. Snails were collected from the selected places of water bodies localised in the surroundings of cooperating health facilities, as described earlier. For this purpose scoop from steel sieves was used. Snails were then placed into a collecting pot containing water from the habitat, and supporting data such as date and time of collection, water and air temperature as well as site and weather conditions were recorded. After identification of snails based on shell morphological characteristics, cercaria shedding test was performed. The snails were placed in 24-well culture plates individually and exposed to indirect sunlight for 2 hours to induce cercaria shedding. The wells of the plates were then examined for the presence of cercariae under a binocular microscope (magnification 40x). Visually identified cercariae were then captured in $2 \mu \mathrm{l}$ of fresh water and pipetted onto sample areas of Whatman Elute FTA micro cards.

Moreover, Whatman FTA Elute cards were used to trap the genetic material of the snails (hemolymph), keeping it stable and safe at room temperature and easily transportable. The presence of prepatent stadium of parasite in $B$. globosus snails was then tested by polymerase chain reaction (PCR).

Table 1. Basic characteristic of study group.

\begin{tabular}{lc}
\hline & $\mathrm{n}(\%)$ \\
\hline Female & $323(71.62 \%)$ \\
Male & $128(28.32 \%)$ \\
\hline Age & $7(1.55 \%)$ \\
\hline Less than 10 years & $106(23.50 \%)$ \\
$10-15$ years & $65(14.41 \%)$ \\
$16-20$ years & $57(12.64 \%)$ \\
$21-26$ years & $98(21.73 \%)$ \\
$27-35$ years & $118(26.16 \%)$ \\
36 and more years & \\
\hline Study area & $117(25.94 \%)$ \\
\hline Mwachinga Dispensary & $124(27.49 \%)$ \\
Mwaluphamba Disp. & $122(27.05 \%)$ \\
Bilashaka Dispensary & $88(19.51 \%)$ \\
Mbuwani Dispensary &
\end{tabular}


Table 2. Presence of $S$. haematobium eggs in urine by gender and study area, $n=451$.

\begin{tabular}{|c|c|c|c|}
\hline Gender & Negative & Positive & $p$-value; $X^{2}$ \\
\hline Female & & & $0.483168 ; 0.4917^{*}$ \\
\hline Mwachinga Dispensary & $74(22.91 \%)$ & $7(2.17 \%)$ & \\
\hline Mwaluphamba Disp. & $66(20.43 \%)$ & $18(5.57 \%)$ & \\
\hline Bilashaka Disp. & $73(22.60 \%)$ & $21(6.50 \%)$ & \\
\hline Mbuwani Disp. & $63(19.50 \%)$ & $1(0.31 \%)$ & \\
\hline Total $(n=323)$ & $276(85.45 \%)$ & $47(14.55 \%)$ & \\
\hline \multicolumn{4}{|l|}{ Male } \\
\hline Mwachinga Dispensary & $29(22.66 \%)$ & $7(5.47 \%)$ & \\
\hline Mwaluphamba Disp. & $31(24.22 \%)$ & $9(7.03 \%)$ & \\
\hline Bilashaka Disp. & $22(17.19 \%)$ & $6(4.69 \%)$ & \\
\hline Mbuwani Disp. & $24(18.75 \%)$ & $0(0.00 \%)$ & \\
\hline Total $(n=128)$ & $106(82.81 \%)$ & $22(17.19 \%)$ & \\
\hline \multicolumn{4}{|l|}{ Study area } \\
\hline Mwachinga & $103(88.03 \%)$ & $14(11.97 \%)$ & \\
\hline Mwaluphamba & $97(78.23 \%)$ & $27(21.77 \%)$ & \\
\hline Bilashaka & $95(77.87 \%)$ & $27(22.13 \%)$ & \\
\hline Mbuwani & $87(98.86 \%)$ & $1(1.14 \%)$ & \\
\hline Total & $382(84.70 \%)$ & $69(15.30 \%)$ & \\
\hline \multicolumn{4}{|l|}{ Mwachinga Dispensary } \\
\hline Less than 10 years & $0(0.00 \%)$ & $1(100 \%)$ & \\
\hline $10-15$ years & $23(79.31 \%)$ & $6(20.69 \%)$ & \\
\hline $16-20$ years & $13(86.67 \%)$ & $2(13.33 \%)$ & \\
\hline $21-26$ years & $9(81.82 \%)$ & $2(18.18 \%)$ & \\
\hline $27-35$ years & $27(93.10 \%)$ & $2(6.90 \%)$ & \\
\hline 36 and more years & $31(96.88 \%)$ & $1(3.12 \%)$ & \\
\hline Total & $103(88.03 \%)$ & $14(11.97 \%)$ & \\
\hline \multicolumn{4}{|c|}{ Mwaluphamba Dispensary } \\
\hline Less than 10 years & $5(83.33 \%)$ & $1(16.67 \%)$ & \\
\hline $10-15$ years & $31(75.61 \%)$ & $10(24.39 \%)$ & \\
\hline $16-20$ years & $23(79.31 \%)$ & $6(20.69 \%)$ & \\
\hline $21-26$ years & $12(80.00 \%)$ & $3(20.00 \%)$ & \\
\hline $27-35$ years & $11(78.57 \%)$ & $3(21.43 \%)$ & \\
\hline 36 and more years & $15(78.95 \%)$ & $4(21.05 \%)$ & \\
\hline Total & $97(78.23 \%)$ & $27(21.77 \%)$ & \\
\hline \multicolumn{4}{|l|}{ Bilashaka Dispensary } \\
\hline Less than 10 years & $0(0.00 \%)$ & $0(0.00 \%)$ & \\
\hline $10-15$ years & $16(69.57 \%)$ & $7(30.43 \%)$ & \\
\hline $16-20$ years & $9(75.00 \%)$ & $3(25.00 \%)$ & \\
\hline $21-26$ years & $14(82.35 \%)$ & $3(17.65 \%)$ & \\
\hline $27-35$ years & $28(82.35 \%)$ & $6(17.65 \%)$ & \\
\hline 36 and more years & $28(77.78 \%)$ & $8(22.22 \%)$ & \\
\hline Total & $95(77.87 \%)$ & $27(22.13 \%)$ & \\
\hline \multicolumn{4}{|l|}{ Mbuwani Dispensary } \\
\hline Less than 10 years & $0(0.00 \%)$ & $0(0.00 \%)$ & \\
\hline $10-15$ years & $13(100.00 \%)$ & $0(0.00 \%)$ & \\
\hline $16-20$ years & $9(100.00 \%)$ & $0(0.00 \%)$ & \\
\hline $21-26$ years & $13(92.86 \%)$ & $1(7.14 \%)$ & \\
\hline $27-35$ years & $20(100.00 \%)$ & $0(0.00 \%)$ & \\
\hline 36 and more years & $32(100.00 \%)$ & $0(0.00 \%)$ & \\
\hline Total & $87(98.86 \%)$ & $1(1.14 \%)$ & \\
\hline
\end{tabular}

${ }^{*} p$-value and $X^{2}$ is related to differences between males and females altogether 
PCR detection of S. haematobium DNA from B. globosus

For DNA extraction a $3 \mathrm{~mm}$ disc containing the sample was punched out of the Whatman FTA Elute cards (GE Whatman, Maidstone, Kent, United Kingdom). The discs were then placed into a microcentrifuge tubes containing $500 \mu$ of PCR water and vortexed 3 times for 5 seconds at high speed. After removal of excess wash water from the tubes, $35 \mu$ of PCR water was added to the punch. Samples were incubated at $95{ }^{\circ} \mathrm{C}$ for $30 \mathrm{~min}$ and then centrifuged to separate the matrix from the eluate containing DNA. Using sterile pipette tips, the discs were removed from the tubes and discarded.

Primers for two PCR assays were designed on the basis of previously published sequence information (Amarir et al., 2014). Dral PCR was performed using commercially available readyto use mastermix My Taq ${ }^{\top M}$ Mix, 2x (Bioline, London, UK), Dral primers (forward: GATCTCACCTATCAGACG, reverse: GTCACCAATAATATGAAAC), and target DNA.

To distinguish $S$. haematobium from other relative species - e.g., $S$. bovis, which is sympatric with $S$. haematobium in many endemic areas - the DNA of Dral positive snails were analysed

by Sh110/SmSI PCR that was unique for S. haematobium. The primer combination used included Sh110 primer: 5'- TTC CTC CAA CTA CCA TCT TAT CTC-3'and Sm-SI primer: 5'- AAC CGT CAC GGT TTT ACT CTT GTG-3'. PCR conditions for both assays were set at $95^{\circ} \mathrm{C}$ for $5 \mathrm{~min}$ for initial denaturation, followed by 35 cycles of $95^{\circ} \mathrm{C}$ for $1 \mathrm{~min}$ (denaturation), 35 cycles of $55^{\circ} \mathrm{C}$ for 1 min (annealing) and 35 cycles of $75^{\circ} \mathrm{C}$ for 1 min (extension). Using UV trans-illumination, the amplified products then were visualized on $1.5 \%$ agarose gel stained with fluorescent nucleic acid dye GelRed ${ }^{\mathrm{TM}}$.

\section{Data analysis}

Basic descriptive analysis was performed, differences in proportions were compared by the Chi square $(x 2)$ test using R software, version 3.4.0. Statistical significance was set at a $p$-value of 0.05 .

\section{Ethical Approval}

The authors assert that all procedures contributing to this work comply with the ethical standards of the relevant national and institutional committees on human experimentation and with the Helsinki Declaration of 1975, as revised in 2008.

\section{Results}

From February 19 - March 16, 2018 a total of 451 participants (323 women and $128 \mathrm{men}$ ) were involved into the study. The research team examined 117 samples in Mwachiga Dispensary, 124 in Mwaluphamba Dispensary, 122 in Bilashaka Dispensary and 88 in Mbuwani Dispensary. The basic characteristic of the study group is presented in Table 1.

The presence of $S$. haematobium eggs was detected in urine specimens of $15.30 \%$ (69 out of 451) of study participants altogether; $11.97 \%$ (14 out of 117 ) in urine samples of participants in Mwachinga Dispensary, 21.77 \% (27 out of 124) in Mwaluphamba Dispensary and $22.13 \%$ (27 out of 122) in Bilashaka Dispensary. In Mbuwani Dispensary we detected the presence of $S$. haematobium eggs only in one urine sample $(1.14 \%)$.

Of 451 participants (323 women and 128 men) who were examined for the presence of eggs in urine samples, 47 women and 22 men were detected as schistosomosis positive. Men (17.19\%) had a slightly higher rate of infection than women $(14.55 \%)$, but this difference was not statistically significant $\left(X^{2}=0.48 ; p=0.49\right)$ (Table 2).

Out of 451 of study participants $53(11.75 \%)$ reported access to borehole water, the rest of them used ponds, lakes, rivers, backwaters, or water from tanks as a source of household water or water for animals. The significantly higher infection rate was found among participants who used environmental water sources such as rivers, ponds, or backwaters (14.6\%) in comparison to those, who reported access to the borehole water $(0.6 \%)$ for household purposes or as a source of water for animals $\left(X^{2}=4.99\right.$; OR $=$ $5.04 ; 95 \% \mathrm{Cl} 1.19-21.24 ; p=0.025)$. Similarly, participants living in traditional houses made of mud showed a significantly higher number of Schistosoma infection cases than those living in concrete houses $\left(X^{2}=5.18 ; \mathrm{OR}=2.18 ; 95 \% \mathrm{Cl} 95 \% 1.13-4.22 ; \mathrm{p}\right.$ $=0.02$ ).

The comparison between haematuria and infection status revealed, that 47 individuals (out of 69 ) with detected S. haematobium eggs in the urine samples were screened positive for haematuria, whereas the rest $(n=22)$ had no sign of haematuria. Inversely, 97 of the participants were found to be $S$. haematobium infection negative, although they demonstrated haematuria and 284 were both infection and haematuria negative.

The presence/absence of $S$. haematobium eggs in the urine with/ without haematuria is shown in Table 3.

Table 3. The presence/absence of $S$. haematobium eggs in the urine with/without haematuria.

\begin{tabular}{cccc}
\hline & Eggs pos. & Eggs neg. & Total \\
Haematuria pos. & $47(10.42 \%)$ & $97(21.5 \%)$ & 144 \\
Haematuria neg. & $22(4.87 \%)$ & $285(63.19)$ & 307 \\
Total & 69 & 382 & $451(100 \%)$ \\
\hline
\end{tabular}

Sensitivity rate $=68 \%$, specificity rate $=74 \%$, positive predictive value $=32 \%$, negative predictive value $=92 \%$, validity $=74 \%$. 
Table 4. Presence of $B$. globosus and cercaria shedding test results in selected local water resources.

\begin{tabular}{|c|c|c|c|c|}
\hline $\begin{array}{l}\text { Date of } \\
\text { collection }\end{array}$ & Locality/area & Water source & $\begin{array}{c}\text { B. globosus } \\
\text { (n) }\end{array}$ & Cercaria shedding test \\
\hline 23.02 .18 & Mwachinga & Mbeto river & 0 & - \\
\hline 23.02 .18 & Mwachinga & Kombo river & 0 & _- \\
\hline 26.02 .18 & Mwachinga & Bora river & 31 & neg. \\
\hline 27.02 .18 & Mwachinga & Ndugunane river & 10 & neg. \\
\hline 28.02 .18 & Mwachinga & Jarumani river & 13 & neg. \\
\hline 01.03 .18 & Mwachinga & Ramoyo river & 21 & neg. \\
\hline 02.03 .18 & Mwaluphamba & Bechone Swabirina river & 27 & neg. \\
\hline 02.03 .18 & Mwaluphamba & Pengo river & 23 & pos. \\
\hline 05.03 .18 & Mwaluphamba & Mbadzi river & 0 & - \\
\hline 05.03 .18 & Mwaluphamba & Bangoni river & 11 & pos. \\
\hline 06.03 .18 & Mwaluphamba & Tsanganyiko river & 30 & pos. \\
\hline 07.03 .18 & Mwaluphamba & Komanazilale & 3 & neg. \\
\hline 08.03 .18 & Mwaluphamba & Mzizima river & 0 & - \\
\hline 12.03 .18 & Bilashaka & Buburu river, 1. site & 28 & neg. \\
\hline 12.03 .18 & Bilashaka & Buburu river, 2. site & 15 & neg. \\
\hline 13.03.18 & Bilashaka & Kivumiro river, site 1 & 5 & neg. \\
\hline 13.03 .18 & Bilashaka & Kivumiro river, site 2 & 5 & neg. \\
\hline 14.03 .18 & Bilashaka & Chimambani river & 32 & neg. \\
\hline 15.03.18 & Bilashaka & Mbararani river, 1. site & 11 & neg. \\
\hline 15.03 .18 & Bilashaka & Mbararani river, 2. site & 24 & neg. \\
\hline
\end{tabular}

However, after stratification of the intensity of $S$. haematobium infection by light $(n=50)$, medium $(n=10)$ and heavy $(n=9)$, it was seen that all cases of heavy infections (i.e., 50 or more eggs $/ 10 \mathrm{ml}$ of urine) were connected with documented haematuria in the urine samples.

Nine of 69 infection-positive and 36 of infection-negative participants reported treatment with praziquantel in the past 6 months. There was no significant difference between infection positivity of treated and un-treated group of patients $\left(X^{2}=0.85 ; \mathrm{OR}=1.44\right.$; $95 \% \mathrm{Cl} 0.66-3.15 ; p=0.36)$. Nine infection-positive participants belonged to the age group $10-15$ years; 29 infection positive participants were in age group $16-20$ years, 11 in age group $20-25$ years, 10 in age group $26-35$ years, 9 were older than 36 years and 1 positive participant was 6 years old.

Intermediate host of infection in these regions - B. globosus - was found in 10 out of 16 screened water resources. Cercaria shedding test was positive in 2 particular sites of river Pengo and Tsanganyiko (Table 4).

Genetic material of 68 B. globosus snails tested by Dral PCR revealed 7 positive samples. Confirmation by Sh110/SmSI PCR showed that 6 of 7 Dral positive snails were infected by $S$. haematobium. The positive snails came from the rivers Mbararani, Buburu, Kiwumiro and Bangoni.

\section{Discussion}

Efforts to control morbidity of schistosomosis as well as other helminthosis is increasing in many countries of sub-Saharan Africa, including Kenya - School Based Deworming Programme is one of the main tool of control focused on regular administration of a single dose of anthihelminth drugs to school-aged children. At the end of the twentieth century the prevalence of $S$. haematobium infection was $>70 \%$ among school-aged children in Kwale County, Kenya (King et al., 1988, Sato et al., 1988). Recent publications refer that more than $30 \%$ of schoolchildren could be infected with S. haematobium in this part of Kenya (Bustinduy, 2013, Chadeka, 2017, Njenga, 2014). In the framework of deworming programme, in Mwaluphamba, Bilashaka and Mbuwani, co-administration of praziquantel (against urinary schistosomiasis) and albendazole (against soil-transmitted helminth infections) to community and school children was performed once a year in follwoing years: 2004, 2005,2007, 2009 and 2012. To date, praziquantel is applied in these areas to school-children once a year. In Mwachinga, praziquantel was administered to both school children and community yearly from $1998-2007$. From 2010 to date, it is applied to school-children once a year.

However, this regular treatment approach cannot interrupt schis- 
tosomosis transmission, as is indicated by a number of authors (Njenga et al., 2014; Adenowo et al., 2015; Sokolow et al.,2016). This is congruent also with our study conducted in Kwale County, Kenya in February-March, 2018. Our survey revealed some areas with a higher proportion of study participants infected with $S$. haematobium (i.e., the catchment areas of Mwachinga, Mwaluphamba and Bilashaka Dispensaries with $11.96 \%, 20.96 \%$ and $22.13 \%$ of infected individuals, respectively), while the other locality surveyed (catchment area of Mbuwani Dispensary) showed only a very slight proportion of infected subjects $(1.13 \%)$. The focal character of schistosomosis transmission was documented by a number of relevant publications (Brooker, 2002; Clennon et al., 2006; Meurs et al., 2013; Chadeka et al., 2017), suggesting a public health problem in geographically restricted localities. The difference between men and women in the prevalence of schistosomosis was not statistically significant (17.18\% and $14.55 \%$, respectively; $p$ $=0.48$ ). However, there was a higher sex ratio in favor of women among the participants in our study, which was caused by the proportion of patients in primary health care facilities, focusing mainly on reproductive, maternal and child health care services.

The results of studies dealing with gender effect on the prevalence of urinary schistosomosis are inconsistent, moreover, the majority of them were evaluating data collected from school children or preschool children, in contrast to our study, in which also older age categories were included (Nkegbe et al., 2010; Ekpo et al., 2011; Kayuni et al.,2017). Males may be involved in water-contact activities such as cattle watering, preparing materials for construction of buildings or farming, while females in laundry, household cleaning and other domestic works - with no diffefence in exposure to the risk factor. The significantly higher infection rate was found among participants who used environmental water sources as rivers, ponds, or backwaters in comparison to those, who reported access to the borehole water for household purposes or as a source of water for animals $\left(X^{2}=4.99 ; O R=5.04 ; 95 \% \mathrm{Cl} 1.19\right.$ 21.24; $p=0.025)$. This is consistent with Singh et al. (2016), who in Sokoto, Nigeria, reported higher occurrence of urinary schistosomosis among those using dam water as a water supply for drinking $(75.24 \%)$ in comparison to those who used water from boreholes (17.64 \%). Also Grimes et al. (2014) who carried out a systematic meta-analysis of studies reporting $S$. haematobium infection rate suggested, that safe water supplies were associated with significantly lower odds of schistosomosis. In contrast to these findings, Kholy et al. (1989) state that borehole well introduction had minimal impact on transmission of schistosomosis in 3 endemic villages in Kenya. Also Mutuku et al.(2011) indicate, that residents in some infection areas might prefer pond and river water for laundry and bathing over the hard water from borehole wells.

The significantly higher rate of detected schistosomosis in participants living in traditional mud houses found in our study $\left(X^{2}=5.18\right.$; $\mathrm{OR}=2.18 ; 95 \% \mathrm{Cl} 95 \% 1.13-4.22 ; p=0.02$ )

may be connected with a lower socioeconomic status of their inhabitants rather than the construction material itself. Sady et al.
(2013) indicated, that low household monthly income was one of the key factors significantly associated with schistosomosis among children in rural areas in Yemen. An association between schistosomosis and socioeconomic conditions was pointed out also by study of Ximenes et al. (2006). Socioeconomic development connected with implementation of adequate water supply, sewage system, sanitation facilities and health education could have permanent positive effect on the control of schistosomosis (Ximenes, 2006; Sady, 2013).

In highly endemic areas, detection of hematuria could serve as a proxy indicator for $S$. haematobium infection identification (Anosike et al. 2001; French et al. 2007; Houmsou et al. 2011). The validity of haematuria as a diagnostic criterion for urinary schistosomosis screening was discussed in a number of publications (Kinget al., 2013; Krauth et al. 2015; Ochodoet al., 2015; Knopp et al., 2018). In our study, dipstick test sensitivity and specificity for detection of egg-positive urine were estimated at $68 \%$ and $74 \%$, respectively (Table 3). However, after stratification of the intensity of $S$. haematobium infection by light, medium and heavy, we observed a substantial increase in the sensitivity rate of the dipstick test in heavy infections. This is in agreement with the results of other studies (King et al.,2013; Krauth et al., 2015), which found that the sensitivity of the hematuria test is reduced in groups with light intensity infections.

Nine of 69 infection-positive participants reported medication with praziquantel in the past 6 months. All of these 9 participants belonged to the age group $10-15$ years, so they were involved in the programme of MDA to school-aged children. However, after a treatment with praziquantel, they might get re-infected during their contact with water infested with $S$. haematobium positive intermediate hosts. Infected study participants excluded from deworming programme may contribute to water infestation via excreted parasite ova.

In order to estimate disease transmission, suspected water bodies localised in the surroundings of cooperating health facilities were monitored. After scooping, snails of the genus Bulinus were morphologically identified and cercaria shedding test was performed. The intermediate host of infection - B. globosus - was found in 10 out of 16 screened water resources. The cercaria shedding test was positive in 2 particular sites of river Pengo and Tsanganyiko. Moreover, from the genetic material (haemolymph) trapped on FTA cards, the presence of prepatent stages of $S$. haematobium in B. globosus was detected by two PCR assays (Dral PCR and Sh110/Sm-SI PCR) using primers according to Amarir et al. (2014). These reactions, which enabled differentiation of Schistosoma haematobium DNA from DNA of related Schistosoma spp. (e.g., S. bovis, which is sympatric with $S$. haematobium in many endemic areas), revealed infected snails also at the river Buburu, Mbararani, Kiwumiro and Bangoni.

The results of our study indicate that the treatment strategy focusing only on MDA to school age children cannot interrupt the transmission of the disease. Since most affected people live in 
simple dwellings without running water, they will inevitably come into contact with water contaminated by cercariae when bathing, washing clothes or watering animals. Recently, therefore, many authors have emphasized the need for integrated control measures, including regulation of the number of intermediate hosts, access to clean water and health education as a complement to MDA (Sokolow, 2016; Ross, 2017). Furthermore, the World Health Assembly (WHA) in its resolution called for the implementation of complementary, non-pharmaceutical control strategies to eliminate this disease (WHA, 2012).

In conclusion, schistosomosis was still present in the study area, although the majority of positive participant had light form of infection. Transmission of diseases was not interrupted and continued to take place in some areas of reasearch. The rate of infection was significantly influenced by type of housing and water supplies used for indoor and outdoor household purposes. Preventive measures should consider that MDA to school children as well as implementation of adequate water supply, sewage system, sanitation facilities and health education could have positive impact on the control of schistosomosis.

\section{Acknowledgements}

Our appreciation goes to all participants of the study. We also thank to the Ministry of education, science, research and sport of the Slovak Republic for the funding of the project and the head of Specific Department of FHSaSW TU in Kenya in Kwale region, Kenya, Dr. Zuzana Král'ová, PhD., for management of cooperation with KEMRI-NUIT workers, Kwale, Kenya. We are also gratful to Mrs. Viera Mišurová and Mr. Moses Whakungu Machimbo for excelent technical assistance and to Dr. Mark Steven Taylor for his linguistic review of the manuscript. In addition, we acknowledge the support offered by grant KEGA no. 013TTU-4/2019.

\section{Conflict of Interest}

Authors have no potential conflict of interest pertaining to this submission to Helminthologia.

\section{References}

Adenowo, A.F., Oyinloye, B.E., Ogunyinka, B.I., Kappo, A.P. (2015): Impact of human schistosomiasis in sub-Saharan Africa. Braz. J. Infect. Dis., 19(2): 196 - 205. DOI: 10.1016/j.bjid.2014.11.004 Amarir, F., Sebti, F., Abbasi, I., Sadak, A., Fellah, H., Nhammi, H., Ameur, B., El IdrISSI, A.L., Rhajaoul, M. (2014): Schistosoma haematobium detection in snails byDral PCR and Sh110/Sm-SI PCR: Further evidence of the interruption of schistosomiasis transmission in Morocco. Parasit Vectors., 7. DOI:10.1186/1756-3305-7-288 ANosike, J.C., Nwoke, B.E.B., NJoku, A.J. (2001): Validity of haematuria in the community diagnosis of urinary schistosomiasis infection. J. Helminthol., 75(3): 223 - 225. DOI: 10.1079/JOH200048
BROOKER, S. (2002): Schistosomes, snails and satellites. Acta Trop., 82(2): 207 - 214. DOI: 10.1016/S0001-706X(02)00012-8 Bruun, B., AagaARD-Hansen, J. (2008):The social context of schistosomiasis and its control: an introduction and annotated bibliography. $1^{\text {st }}$ Edition, Geneva, Switzerland, World Health Organization, $213 \mathrm{pp}$.

Bustinduy, A.L., Parraga, I.M., Thomas, C.L., Mungal, P.L., Mutuku, F., MuchirI, E.M., KITRON, U., KING C.H. (2013): Impact of polyparasitic infections on anemia and undernutrition among Kenyan children living in a Schistosoma haematobium-endemic area. Am. J. Trop. Med. Hyg., 88(3): 433-40. DOI: 10.4269/ajtmh.12-0552 Chadeka, E., Nagi, S., Sunahara, T., Cheruiyot, N., Bahatı, F., Ozekı, Y., Inoue, M., Osada-OKa, M., Okabe, M., Hirayama, Y., Changoma, M., Adachi, K., Mwende, F.,Kikuchi, M., Nakamura, R., Kalenda, Y., Kaneko, S., HiRayama, K., Shimada, M., Ichinose, Y., Nuenga, S., Matsumoto, S., Hamano, S. (2017): Spatial distribution and risk factors of Schistosoma haematobium and hookworm infections among schoolchildrenin Kwale, Kenya. PLoS Negl. Trop. Dis., 11(9): e0005872. DOI: 10.1371/ journal.pntd.0005872

Clennon, J.A., Mungal, P.L., Muchiri, E.M. , King, C.H., Kitron, U.(2006): Spatial And TemporalVariations In Local Transmission Of Schistosoma Haematobium In Msambweni, Kenya. Am. J. Trop. Med. Hyg. , 75(6): 1034 - 1041. DOI: 10.4269/ajtmh.2006.75.1034 Ekpo, U., Alabi, O., Oluwole, A. , Sam-Wobo, S. (2012): Schistosoma haematobium infections in preschool children from two rural communities in ljebu East, south-western Nigeria. J. Helminthol., 86(3): 323 - 328. DOI: 10.1017/S0022149X11000459

El RidI, R.A., TAllima, H.A. (2013): Novel therapeutic and prevention approaches for Schistosomiasis: Review. J. Adv. Res., 4(5): 467 - 478. DOI: 10.1016/j.jare.2012.05.002

French, M., Rollinson, D., Basáñez, M., Mgeni, A., Khamis, I., StoTHARD, J.(2007):School-based control of urinary schistosomiasis on Zanzibar, Tanzania: Monitoring micro-haematuria with reagent strips as a rapid urological assessment. J. Pediatr. Urol., 3(5): 364368. DOI: 10.1016/j.jpurol.2007.01.198

Grimes, J.E., Croll, D., Harrison, W.E., Utzinger, J., Freeman, M.C., Templeton, M.R. (2014): The Relationship between Water, Sanitation and Schistosomiasis: A Systematic Review and Meta-analysis. PLoS Negl. Trop. Dis., 8(12): e3296. DOI:10.1371/ journal.pntd.0003296

Gryseels, B., Polman, K., Clerinx, J., Kestens, L. (2006): Human schistosomiasis. Lancet, 368(9541): 1106 - 1118. DOI: 10.1016/ S0140-6736(06)69440-3

Houmsou, R., Kela, S., Suleiman, M. (2011): Performance of microhaematuria and proteinuria as measured by urine reagent strips in estimating intensity and prevalence of Schistosoma haematobium infection in Nigeria. Asian. Pac. J. Trop. Dis., 4(12):997-1000. DOI: 10.1016/S1995-7645(11)60233-2

Kayuni, S., Peeling, R., Makaula, P. (2017): Prevalence and distribution of Schistosoma haematobium infection among school children living in southwestern shores of Lake Malawi. Malawi Med. J., 29(1):16 - 23. DOI: 10.4314/mmj.v29i1.4 
Kholy, H.E., King, C.H., Koech, D., Sturrock, R.F., Siongok, T.K., Mahmoud, A.A., Houser, H. (1989): Effects of Borehole Wells on Water Utilization in Schistosoma haematobium Endemic Communities in Coast Province, Kenya. Am. J. Trop. Med. Hyg., 41(2): 212 - 219. DOI:10.4269/ajtmh.1989.41.212

KING, C., BERTSCH, D. (2013): Meta-analysis of Urine Heme Dipstick Diagnosis of Schistosoma haematobium Infection, Including Low-Prevalence and Previously-Treated Populations. PLoS Negl. Trop. Dis., 7(9):e2431. DOI: 10.1371/journal.pntd.0002431

King, C.H., Lombardi, G., Lombardi, C., Greenblatt, R., Hodder, S., Kinyanjul, H., Ouma, J., Odiambo, O., Bryan, P.J., Muruka, J.(1988): Chemotherapy-based control of schistosomiasis haematobia. I. Metrifonate versus praziquantel in control of intensity and prevalence of infection. Am. J. Trop. Med. Hyg., 39(3): 295-305. DOI: 10.4269/ajtmh.1988.39.295

Knopp, S., Ame, S., Hattendorf, J., Ali, S., Khamis, I., Bakar, F., Khamis, M., Person, B., Kabole, F., Rollinson, D. (2018):Urinary schistosomiasis elimination in Zanzibar: accuracy of urine filtration and haematuria reagent strips for diagnosing light intensity Schistosoma haematobium infections. Parasit. Vectors, 11. DOI: 10.1186/s13071-018-3136-6

Krauth, S., Greter, H., Stete, K., Coulibaly, J., Traoré, S., Ngandolo, B., Achl, L., Zinsstag, J., N'goran, E., Utzinger, J. (2015): All that is blood is not schistosomiasis: experiences with reagent strip testing for urinary schistosomiasis with special consideration to very-low prevalence settings. Parasit. Vectors, 8.DOI: 10.1186/ s13071-015-1165-y

Meurs, L., Mbow, M., Boon, N., Van Den Broeck, F., Vereecken, K., Dièye, T., AвatiH, E., Huyse, T., Mboup, S., Polman, K. (2013): Micro-Geographical Heterogenity in Schistosoma mansoni and $S$. haematobium Infection and Morbidity in a Co-Endemic Community in Northern Senegal. PLoS Negl. Trop. Dis., 7(12):e2608. DOI: 10.1371/journal.pntd.0002608

Mutuku, F., Bustinduy, A., King, C., Kitron, U., Muchirl, E., Mungal, P. (2011): Impact of Drought on the Spatial Pattern of Transmission of Schistosoma haematobium in Coastal Kenya. Am. J. Trop. Med. and Hyg., 85(6): 1065 - 1070. DOI: 10.4269/ajtmh.2011.11-0186

Muhumuza S., Olsen A., Katahoire, A., Kiragga, A.N., Numaha, F. (2014): Effectiveness of a pre-treatment snack on the uptake of mass treatment for schistosomiasis in Uganda: A cluster randomized trial. PLoS Med., 11(5): e1001640. DOI: 10.1371/journal. pmed. 1001640

NJenga, S.M., Mutungl, F.M., Wamae, C.N., Mwanje, M.T., Nuiru, K.K., BoCKARIE, M.J. (2014): Once a year school-based deworming with praziquantel and albendazole combination may not be ad- equate for control of uro genital schistosomiasis and hookworm infection in Matuga District, Kwale County, Kenya. Parasit. Vectors, 7.DOI: 10.1186/1756-3305-7-74

N'Goran, E.K., Gnaka, H.N., TANner, M., Utzinger, J. (2003): Effcacy and side-effects of two praziquantel treatments against Schistosoma haematobium infection, among school children from Côte d'Ivoire. Ann. Trop.Med. Parasitol., 97(1): 37-51. DOl: 10.1179/000349803125002553

NKEGBE, E. (2010): Sex prevalence of schistosomiasis among school children in five communities in the lower river Volta basin of South Eastern Ghana. Afr. J. Biomed. Res., 13: 87-88.

Ochodo, E.A., Gopalakrishna, G., Spek, B., Reitsma, J.B., Van Lieshout, L., Polman, K., Lamberton, P., Bossuyt, P.M., Leeflang, M.M. (2015): Circulating antigen tests and urine reagent strips for diagnosis of active schistosomiasis in endemic areas. Cochrane Database Syst. Rev., (3): 1 - 292. DOI:10.1002/14651858. CD009579.pub2

Ross, A.G., Chau, T.N., Inobaya, M.T., Olveda, R.M., LI, Y., Harn, D.A. (2017): A new global strategy for the elimination of schistosomiasis. Int. J. Infect. Dis., 54: 130-137. DOI:10.1016/j.ijid.2016.09.023 Sady, H., Al-Mekhlafi, H.M., Mahdy, M.A., Lim, Y.A., Mahmud, R., SuRIN, J. (2013): Prevalence and associated factors of schistosomiasis among children in Yemen: implications for an effective control programme. PLoS Negl. Trop. Dis., 7(8): e2377.DOI:10.1371/ journal.pntd.0002377

Sato, K., Shimada, M., Noda, S., Muhoho, N.D., Katsumata, T., Sato, A., AoKI, Y. (1988): Efficacy of metrifonate in a highly endemic area of urinary schistosomiasis in Kenya. Am. J. Trop. Med. Hyg., 38(1): 81-5. DOI: 10.4269/ajtmh.1988.38.81

SINGH, K., MudDASIRU, D., SinGH, J. (2016): Current status of schistosomiasis in Sokoto, Nigeria. Parasite Epidemiol. Control, 1(3): 239 - 244. DOI: 10.1016/j.parepi.2016.08.003

Sokolow, S.H., Wood, C.L., Jones, I.J., SWARTZ, S.J., LOPEZ, M., Hsieh, M.H., Kevin, D., Lafferty, K.D., KuRIS, A.M., De Leo, G.A. (2016): Global Assessment of Schistosomiasis Control Over the Past Century Shows Targeting the Snail Intermediate Host Works Best. PLoS Negl. Trop. Dis., 10(7):e0004794 DOI:10.1371/journal.pntd.0004794

Ximenes, R., Southgate, B., Smith, P.G., Neto, L.G. (2003): Socioeconomic determinants of schistosomiasis in an urban area in the Northeast of Brazil. Rev. Panam. Salud. Publica, 14(6): 409-421. WHA (2012): Elimination of schistosomiasis. Geneva: WHO: WHA65/2012/REC/1Sixty-fifth World Health Assembly: resolutions and decisions annexes 